\title{
A polissemia da expressão convencional cabra a partir de uma metodologia qualiquantitativa
}

\author{
Polysemy of conventional expression cabra based on qualitative and quantitative research
}

\section{Fernanda Carneiro Cavalcanti}

Universidade Federal do Ceará - Fortaleza - Ceará - Brasil

\begin{abstract}
Resumo:Este artigo visa discutir o tipo de metodologia adotada e a análise empreendida em nossa pesquisa de doutorado intitulada A Análise Da Polissemia Da Expressão Convencional Cabra Sob A Perspectiva Dos Modelos Cognitivos Idealizados. $\mathrm{Na}$ introdução, discorremos, de forma sucinta, acerca dos aspectos teóricos que nortearam nossa investigação; e nas três demais seções, abordamos, de um lado, os procedimentos metodológicos de natureza qualiquantitativa por nós adotados; de outro, lado, apresentamos os resultados obtidos seguidos de discussão e conclusão. As considerações finais encerram o artigo revisando as questões relativas aos procedimentos metodológicos abordados bem como as possíveis contribuições que tais procedimentos podem oferecer àqueles que fazem pesquisa em Linguística Cognitiva.
\end{abstract}

Palavras-chave:Linguística cognitiva. Metodologia qualiquantitativa. Polissemia.expressãoconvencionalcabra.

Abstract: This article aims at discussing about the methodology and the analisys developed in my PHD research AnalisysOf Polysemy Of The Conventional Expression Cabra In Light Of Idealized Cognitive Models Theory. Therefore, in the four sections, I discuss about some of the theoretical aspects of this research and some results achieved based on qualitative and quantitative methodology as well. In the conclusion, I review the methodology issues of my research in order to present some contributions in terms of research in Cognitive Linguistics.

Keywords: Cognitive Linguistics. Qualitative and quantitative research.Polysemy. Conventionalexpressioncabra.

\section{Introdução}

Nossa pesquisa intitulada A Análise Da Expressão Convencional Cabra Sob A Perspectiva Da Teoria Dos Modelos Cognitivos Idealizados teve como objeto a polissemia da expressão convencional cabra. Tal expressão, quando usada pelos falantes do Nordeste do Brasil, é considerada polissêmica tanto do ponto de vista da Semântica Lexical quanto do ponto de vista da Semântica Cognitiva. Com efeito, tanto os dicionários gerais como todos os demais dados por nós coletados e analisados apontam para uma compreensão de cabra ora como animal, ora como 'sujeito', 'homem de origem rural e mestiça', 'homem viril', 'valente', 'bom caráter' e até mesmo 'violento'.

No entanto, se para a Semântica lexical, a polissemia é um fenômeno essencialmente linguístico, estruturado a partir de um significado único, geral e abstrato, ou ainda uma coleção de significados independentes; para Semântica Cognitiva, especialmente para Teoria dos Modelos Cognitivos Idealizados (TCMI), formulada por Lakoff (1987), a polissemia é um fenômeno fundamentalmente conceptual estruturado a partir de relações, de caráter sistemático e aberto, entre 
conceitos disjuntos. Ainda para Lakoff (1987), a polissemia deve ser abordada a partir do funcionamento do sistema conceptual humano, especialmente a partir do Modelo Cognitivo Proposicional do tipo Categoria Radial, doravante MCI Proposicional do tipo Categoria Radial. Ou seja, segundoGeeraerts (2009), a polissemia se constituiria em uma relação, de natureza estruturada, entre conceitos disjuntos, sendo essa estrutura do tipo de agrupamento radial.

O $\mathrm{MCl}$ Proposicional do tipo de Categoria Radial é definido, igualmente, por Lakoff (1987) como uma estrutura de centro periferia que não possui apenas uma única representação. Tal estrutura seria, assim, produto de princípios gerais construídos a partir da experiência corpórea humana física e socioculturamente situada e, portanto, não teria estrutura previsível.

Dessa forma, investigamos a polissemia da expressão convencional cabra à luz da TMCl; e à luz da Teoria da Metáfora Conceptual (TMC), inicialmente proposta por Lakoff e Johnson, (1980), a partir particularmente das metáforas animais discutidas por Kövecses (2010), com o objetivo de estabelecer correspondências entre pensamento conceitual, estrutura linguística e cultura.

Em consonância com Lakoff e Turner (1989), Kövecses (2010) afirma que boa parte do comportamento humano parece ser compreendida em termos de comportamento animal com base na Metáfora Conceptual (MC) COMPORTAMENTO HUMANO É COMPORTAMENTO ANIMAL. Em português do Brasill, teríamos, por exemplo, as seguintes expressões linguísticas, licenciadas pela metáfora em questão: 'Ela foi uma vaca comigo'; 'Isso étrairagem'; 'Ele berrou bem alto'; 'As mulheres ficam cacarejando na cozinha'; 'Isso é coisa para quem é tubarão'. No entanto, conforme destacam Lakoff e Turner (1989), os animais seriam essencialmente instintivos, para serem, por exemplo, considerados malvados e desagradáveis como uma vaca; desleais como a traíra, inconvenientes como os bezerros; tagarelas como as galinhas ou truculentos como os tubarões. Assim, Kövecses (2010) pondera que os seres humanos, primeiro, caracterizariam metaforicamente os animais em termos de atributos humanos para, em seguida, se compreenderem em termos de animal.

Kövecses (2010) acrescenta, ainda, que não apenas o comportamento humano é compreendido em termos de comportamento animal como as pessoas são compreendidas em termos de animais. Com base na metáfora PESSOAS SÃO ANIMAIS, poderíamos pensar que foram licenciadas em português do Brasil as seguintes expressões linguísticas em português: 'A jararaca chegou'; 'Não sei como ela se casou com aquele cavalo batizado'; 'Ele é um verme'; 'A vaca da minha chefe não veio hoje'. Assim, para o autor em questão, o significado licenciado pelas metáforas COMPORTAMENTO HUMANO É COMPORTAMENTO ANIMAL e PESSOAS SÃO ANIMAIS parece ser ofensivo. Diante de tal constatação, o autor sugere que as MCs COMPORTAMENTO HUMANO É COMPORTAMENTO ANIMAL E PESSOAS SÃO ANIMAIS sejam, na verdade, perspectivadas com base nas metáforas COMPORTAMENTO HUMANO INDESEJÁVEL É COMPORTAMENTO ANIMAL e PESSOAS ABJETAS SÃO ANIMAIS.

No entanto, Kövecses (2010) pondera ainda que, apesar de grande parte das metáforas animais parecer mapear características negativas dos seres humanos, algumas, dentre elas, não o fariam, a exemplo de MULHER SEXY É GATINHA. Dessa forma, Kövecses (2010) pleiteia a existência, em nosso sistema conceptual, de metáforas animais de nível genérico, isto é, SER HUMANO É ANIMAL e metáforas de nível específico, isto é, PESSOAS ABJETAS SÃO ANIMAIS e PESSOAS SÃO ANIMAIS. Em outras palavras, as metáforas animais seriam metáforas congruentes, já que se constituiriam em um complexo de metáforas, dentre as quais, uma seria de nível genérico e as demais seriam de nível específico. Ademais, Kövecses (2010) observa que seria no âmbito das metáforas de nível específico que ocorreria variação de ordem cultural, já que a metáfora de nível genérico teria caráter universal ou quase universal. 
Nessa perspectiva, objetivamos, com base na polissemia da expressão convencional cabra, examinar as correspondências entre pensamento conceitual, estrutura linguística e cultura a partir das seguintes perguntas:

(i) Em que medida a articulação entre expressão convencional cabra e o compartilhamento de entendimentos entre os membros da cultura fortalezense acerca do papel sociocultural que o animal cabra exerce nessa comunidadenos levaria a compreender quais são os procedimentos cognitivos atuantes na emergência do conceito de um HOMEM CABRA?

(ii) O conceito HOMEM ganharia extensões metafóricas por meio dos significadosde persistência e de resistência tradicionalmente atribuídos ao animal cabra?

(iii) Os processos de natureza corpórea, socioculturalmente motivados que se encontram na base das conceptualizações de membros da comunidade de Fortaleza estariam sendo ativados na construção de uma figura masculina compreendida por meio dos usos da expressão convencional cabra?

\section{Metodologia}

Para o exame da correspondência entre pensamento conceitual, estrutura linguística e cultura a partir da polissemia da expressão convencional cabra, adotamos pesquisa de tipo qualiquantitativa para qual constituímos corpora constituídos de três diferentes gêneros:

I. Definição com base na qual discutimos os vários significados atribuídos à expressão convencional cabra, dentre os quais aqueles que seriam os mais e os menos representativos.

II. Documento literário, com base no qual observamos a variação de uso da expressão em questão.

III. Questionário por ser instrumento tradicionalmente usado em pesquisa de base empírica por meio do qual o pesquisador pode conduzir, ainda que de forma parcial, o processo para obtenção de dados, em especial circunscrever a categoria de sujeitos; estabelecer o tema das perguntas e de que forma elas serão tratadas; determinar as variáveis que são de seu interesse; revisitar os dados dos respondentes para dele extrair outras informações que levem em conta outras variáveis desprezadas em uma determinada etapa.

Dessa forma, em termos de definição, selecionamos sete definições de acordo com a seguinte tipologia: (i) autorizada (Ferreira, 2004); (ii) de senso comum, constantes nos chamados dicionários de cearês (Gadelha, 1999; Pontes, 2000; Saraiva, 2001); e (iii) especializada (Freyre, 2004, Cascudo, 2009; Mello, 2004 apud NETO 2009). Segundo essas definições, o significado não metafórico 'animal'seria o significado prototípico da expressão cabra; e o significado metafórico mais representativo seria 'morador ou originário da zona rural'. Isso porque quatro dentre as sete definições analisadas, a exemplo de Ferreira (2004); Freyre (2004); Cascudo (2009) e Mello (2004 apud NETO 2009, p. 337), apontam para a questão da ruralidade do cabra.

Em seguida, ainda teríamos, na condição de significados metafóricos mais representativos, de um lado, 'sujeito', apontado por Ferreira (2004), Pontes (2000) e Gadelha (1999); de outro lado, 'mestiço', de acordo com Ferreira (2004), Freyre (2004) e Cascudo (2009). Quanto aos significados metafóricos não representativos de cabra, teríamos 'cabra da peste', de acordo com Pontes (2000) e Ferreira (2004), 'capanga', em Ferreira (2004) e Cascudo (2009), ‘cangaceiro' em Ferreira (2004) e Cascudo (2009); e, igualmente, 'cabra véi,' 'galante' para Saraiva (2001), cabra véi, gente fina para Pontes (2000), cabra bom de peia que merece uma surra para Pontes (2000).

Em termos de documento literário, escolhemos quatro romances regionais (Castro, 2006; Olímpio, 1984; e Rêgo, 1982), uma peça de teatro (Suassuna, 2005) e um cordel (Caboclo, 2000) nos quais identificamos 58 ocorrências da expressão cabra que aparecia sozinha ou acompanhada de algum 
modificador, a exemplo de macho, frouxo, safado, etc.. De modo geral, verificamos que a expressão se referia ora à ideia de sujeito, ora à ideia de capanga e cangaceiro. Algumas vezes, ela se referia à ideia de pessoa indeterminada ou gente. Poucas vezes, identificamos a expressão se referindo à mulher, particularmente a mulheres responsáveis pela amamentação dos filhos de dono de engenho.

Em termos de questionário, elaboramos cinco questionários de três, treze, dezesseis, nove e dez perguntas, respectivamente e os aplicamos, em 2010 e 2013, junto a 153 respondentes residentes em Fortaleza, cuja faixa etária varia entre 19 e 55 anos. Embora o perfil dos respondentes seja heterogêneo, a grande parte é constituída de estudantes universitários da Universidade Federal do Ceará e da Universidade de Fortaleza. Quatorze participantes responderam aos questionários via email e 139 o fizeram de forma presencial. Boa parte dos dados levantados com a aplicação dos cinco questionários recebeu tratamento quantitativo, visto que nem todas as perguntas eram passíveis de tratamento percentual (Ver Anexo A).

As questões constantes nos cinco questionários foram elaboradas de acordo com cinco critérios de análise:

I. Imagens mentais suscitadas pela expressão convencional cabra (Ver Anexo A: questão 1 do Quadro 1; questão 7 do Quadro 2; questão 4 do Quadro 3; questão 3 do Quadro 4; questão 3 do Quadro 5);

II. Julgamento do uso da expressão em foco (Ver Anexo A: questão 2 do Quadro 1; questões 4, 6, 12 e 13 do Quadro 2; questões 4, 7 e 8 do Quadro 4; questões 4, 7 e 8 do Quadro 5);

III. Julgamento das definições da expressão em questão (Ver Anexo A questão 3 do Quadro 1; questões 4, 5, 8, 9, 10 e 11 do Quadro 2);

IV. Percepção e crenças acerca da relação homem e animal (Ver Anexo A questões 1 e 2 do Quadro 2; questões 1, 2, 3, 6, 10, 11, 12, 13, 15 e 16 do Quadro 3; questões 1, 2, 5, 6 do Quadro 4; questões 1, 2, 5, 6 e 10 do Quadro 5);
V. Percepção e crenças acerca da linguagem e da cultura (Ver Anexo A questões 5, 7, 8, 9 e 14 do Quadro 3; questão 9 do Quadro 4; questão 9 do Quadro 5).

A análise dos dados se deu em dois momentos: primeiro, em separado; em seguida, na triangulação dos dados obtidos com a análise em separado. Os dados foram analisados de modo que examinássemos:

I. Os significados mais prototípicos e não prototípicos da expressão convencional cabra.

II. As contribuições das normas e conhecimento culturais na emergência do conceito CABRA que licencia a expressão convencional correlata.

III. A maneira pela qual esses significados se estruturam.

\section{Resultado}

A grosso modo, de acordo com os dados coletados, obtivemos os seguintes resultados: para os 153 respondentes, a imagem que lhes vem à mente quando ouvem a palavra 'cabra' é do 'animal', em primeiro lugar, e de 'homem', em segundo lugar (Ver quadro 1). Apesar de não concordarem que o homem nordestino seja representado pela imagem de cabra, tais participantes avaliaram que a expressão 'cabra bom' Ihe evoca imagem de uma pessoa boa e talentosa. Avaliaram, ainda, que a expressão convencional cabra, efetivamente, se refere a homem e, decididamente, não se refere à mulher (Ver quadro 2), além de não concordarem com definições de cabra na condição de morador da zona rural, de mestiço de mulato e negra, de jagunço nem de cangaceiro. (Ver quadro 2).

Ainda segundo os 153 participantes, o homem seria um animal e embora achem que a cabra tem boa aparência, não verificam nenhum tipo de similaridade física entre homem e cabra. Afirmam, contudo, haver similaridade comportamental entre homem e cabra tal qual: temperamento forte, teimosia, valentia, resistência, persistência, força, 
entre outras (Ver quadros 4 e 5). Consideram, como características marcantes da cabra, o berro, os chifres, a resistência, o cheiro, a valentia, a teimosia, o leite, entre outras. Estimam que a cabra tem papel relevante para sociedade na qual vivem tanto no fornecimento de carne, leite e couro como na produção de histórias, vocabulário e expressões (Ver quadros 4 e 5).

Por outro lado, a partir das sete definições e dos cinco documentos literários, observamos que Ferreira (2004) elenca 'habitante de propriedade rural' como um dos significadosmetafóricos do conjunto de cinco significados da expressão convencional cabrareferente a homem.Freyre (2004) reconhece, igualmente, como importante, a relação entre cabra e ruralidade, por enaltecer a importância desse personagem na história social do Nordeste da canade-açúcar. Cascudo (2009) e Mello (2004 apud NETO 2009) também abordam a relação entre cabra e ruralidade, já que o primeiro afirma que cabra é mal visto no folclore sertanejo; ao passo que o segundo descreve cabra como "sertanejo que, em tempo de paz, vive como os demais agregados dos coronéis, cavando a terra seca, plantando e orando aos céus por chuva". (p. 337).

No que tange aos significados metafóricos 'sujeito' e 'mestiço', cabra seria um homem, ou ainda um sujeito de acordo com Gadelha (1999), Pontes (2000) e Ferreira (2004); ao passo que, para Freyre (2004), Cascudo (2009) e mesmo Ferreira (2004), o cabra não seria qualquer tipo de sujeito, Ou seja, Ferreira (2004), além de definir cabra, na condição de sujeito, o define, em primeiro lugar, como mestiço de mulato e negra. Freyre (2004), ao reconhecer o caráter mestiço do cabra, insinua que, mui provavelmente, este teria sido um dos primeiros homens verdadeiramente brasileiros. Um tipo heróico, portanto. Finalmente, para Cascudo (2009) o cabra, na condição de mestiço de mulato e negra, seria considerado um "ente malfejo, traiçoeiro e ingrato".

A polissemia da expressão convencional cabra assim como os graus de representatividade de seus significados foram igualmente assinalados no âmbito dos documentos literários. Verificamos, nesses documentos, que há usos da expressão convencional cabra que se referem a 'sujeito'; a 'cangaceiro'; a 'capanga'; a 'gente'; a 'pau mandado', a'homem com H', a 'senhor de engenho' e 'amigo'. Dessa forma, avaliamos que os usos mais representativos para tal expressão seriam os que se referem a 'sujeito' e a 'cangaceiro'. No entanto, a análise dos mencionados documentos também nos permitiu afirmar que tal expressão se relaciona com a ideia de ruralidade de maneira representativamente importante. Com efeito, os cinco documentos literários por nós analisados tratam da vida e da relação de personagens que residem na zona rural da região setentrional do Brasil.

Em assim sendo, podemos afirmar que, se cabra se refere a 'sujeito' em ambos os gêneros estudados, não há, no entanto, relação entre cabra e mestiço no âmbito dos cincos documentos literários; e que a relação entre cabra e cangaceiro, no âmbito das definições, se apresenta de forma pouco contundente. É plausível, portanto, pleitear que, nos dois gêneros mencionados, os significados metafóricos mais salientes da expressão em foco seriam 'sujeito'e 'morador ou originário da zona rural'

Nessa perspectiva, verificamosque $0 \mathrm{MCl}$ proposicional HOMEM forma, por meio de mapeamentos metonímicos e metafóricos, um agrupamento de modelos (ou agrupamento radial) com os MCI CABRA e HOMEM CABRA, estruturando, assim, a relação polissêmica entre o significado não metafórico 'animal' e os significados metafóricos 'homem', 'cabra da peste', 'cabra macho', 'morador de zona rural', 'mestiço' e 'cangaceiro' a partir de dois esquemas ou entendimentos compartilhados, quais sejam:

I. A partir dos entendimentos compartilhados por parte dos falantes fortalezenses na contemporaneidade, o significado prototípico 'animal' estabelece extensões metafóricas mais próximas com os significados 'homem' (sujeito), 'cabra macho' e 'cabra da peste' e extensões metafóricas menos próximas com os significados 'mestiço, 'morador de zona rural', 'capanga' e 'cangaceiro'. 
II. A partir dos entendimentos compartilhados por parte dos membros da comunidade nordestina rural em dado momento, o significado prototípico 'animal' estabelece extensões metafóricas mais próximas com os significados 'morador da zona rural', 'mestiço' e 'cangaceiro' e extensões metafóricas menos próximas com os significados 'cabra da peste', 'cabra macho' e 'cabra bom'.

Ouainda:

I. De acordo os entendimentos compartilhados pelos falantes fortalezenses, o conceito HOMEM estaria sendo estruturado tanto pela metáfora primária PERSISTIR É MANTERSE ERETO como pela metáfora animal de nível genérico SER HUMANO É ANIMAL, isto é, HOMEM É CABRA, e de nível específico PESSOAS SÃO ANIMAIS, isto é, HOMEM VALENTE, RESISTENTE, DETERMINADO É CABRA; e PESSOAS ABJETAS SÃO ANIMAIS, isto é, HOMEM SERTANEJO, ILETRADO, RÚSTICO É CABRA.

II. De acordo com os entendimentos compartilhados pela comunidade rural nordestina em dado momento, o conceito HOMEM estaria sendo estruturado tanto pela metáfora primária PERSISTIR É MANTERSE ERETO como pela metáfora animal de nível genérico SER HUMANO É ANIMAL, isto é, HOMEM É CABRA, e de nível específico PESSOAS SÃO ANIMAIS, isto é, HOMEM MESTIÇO, ESFORÇADO, VALENTE, SEXUAL, CONFIÁVEL É CABRA; e PESSOAS ABJETAS SÃO ANIMAIS, isto é, HOMEM IRREQUIETO, ARREBATADO, ENDIABRADO É CABRA.

\section{Discussão e Conclusão}

A questão da estruturação dos significados prototípicos e não prototípicos, que analisamos a partir dos três diferentes gêneros foi discutida com base no fato desses significados estarem sendo motivados pela metáfora primária PERSISTIR É MANTER-SE ERETO e pelas metáforas animais congruentes SER HUMANO É ANIMAL, PESSOAS ABJETAS SÃO ANIMAIS E PESSOAS SÃO ANIMAIS no âmbito do $\mathrm{MCI}$ Proposicional HOMEM. Em outras palavras, o conceito CABRA, que estruturaria a relação entre os significados polissêmicos da expressão correlata, se encontraria, por sua vez, estruturado por um inventário de estruturas cognitivas - esquemas e metáforas - isto é pelo $\mathrm{MCl}$ Proposicional HOMEM do tipo Categoria Radial Cabra.

Com efeito, segundo Lakoff (1987), é comum que certo número de $\mathrm{MCl}$ s se combine entre si de modo a formar o que chama de um agrupamento de modelos, ou ainda um agrupamento radial. Nesse sentido, no que pese o caráter multidimensional e radial da polissemia, Lakoff (1987) postula que as MC podem ser abordadas na condição de base experiencial que mapeia os domínios fonte e alvo de dois diferentes MCls. Desse modo, o significado mais prototípico de uma palavra polissêmica seria designado pelo elemento correspondente ao domínio fonte do primeiro $\mathrm{MCl}$ em correspondência com o domínio alvo do segundo $\mathrm{MCl}$.

Considerando que o $\mathrm{MCl}$ Proposicional HOMEM, na condição de agrupamento de modelos, seria constituído pelos $\mathrm{MCI}$ CABRA e $\mathrm{MCI}$ HOMEM CABRA, e que as metáforas animais mapeariam o domínio fonte animal e o domínio alvo homem dos MCls CABRA e o $\mathrm{MCl}$ HOMEM CABRA respectivamente, o significado mais prototípico da polissêmica expressão convencional cabra seria 'animal' e os demais significados metafóricos mais ou menos representativos emergiriam da relação multidimensional entre os vários modelos que formam o agrupamento radial.

Dessa forma, o significado não metafórico 'animal'ocuparia, na condição de subcategoria, o centro da categoria radial Cabra e os demais significados metafóricos se relacionariam com o centro da categoria em função do esquema motivado pelo compartilhamento de entendimento por parte dos membros da comunidade de Fortaleza ou do 
esquema motivado pelo compartilhamento dos entendimentos por parte da comunidade rural nordestina em dado momento.

Em suma, avaliamos que ao se combinar os MCls CABRA e HOMEM CABRA a partir de mapeamentos metonímicos e metafóricos, $\mathrm{O} \mathrm{MCl}$ proposicional HOMEM formaria o agrupamento radial CABRA cuja estrutura variaria a partir do esquema de falantes fortalezenses e do esquema de membros da comunidade rural nordestina em dado momento.

\section{Considerações Finais}

Consoante Lakoff (1987), para tratar da relação entre significados disjuntos de um dado item lexical, ou ainda do fenômeno polissêmico, numa perspectiva semântico-conceptual, se teria que abordar a organização conceptual de um dado sistema conceptual com base no $\mathrm{MCl}$ Proposicional de tipo Categoria Radial.

Dessa forma, ao examinarmos a polissemia da expressão convencional cabra à luz do $\mathrm{MCl}$ Proposicional HOMEM do tipo Categoria Radial Cabra, estimamos ter discutido as correspondências entre pensamento conceptual, linguagem e cultura implicadas na estruturação dos significados da expressão em questão, já que os resultados obtidos com a análise dos dados coletados indicaram que:

- $\quad$ por um lado, o MCI CABRA, especialmente o domínio conceptual fonte ANIMAL mapeia o $\mathrm{MCl}$ HOMEM CABRA, especialmente o domínio conceptual alvo HOMEM, motivados por experiências corpóreas físicas e socioculturalmente situadas por parte de membros da comunidade contemporânea de Fortaleza e por parte dos membros da comunidade rural nordestina;

- por outro lado, o $\mathrm{MCl}$ HOMEM CABRA mapeia metonimicamente $0 \mathrm{MCl}$ Proposicional HOMEM formando, assim, um agrupamento de modelo, ou ainda um agrupamento radial Cabra.
Para tanto, adotamos metodologia do tipo qualiquantitativa, com corpora constituídos por fontes bibliográficas de natureza diversa e de cinco questionários compostos de três, treze, dezesseis, nove e dez, perguntas respectivamente, que foram aplicados junto a 153 respondentes residentes na cidade de Fortaleza, cujos dados coletados receberam tratamento percentual.

Ademais, para o desenvolvimento de nossa pesquisa de tipo qualiquantitativa, levamos em consideração alguns dos desafios preconizados por Gibbs (2009) que, na condição de psicolinguista experimental, pondera sobre a fragilidade de pesquisas do tipo qualitativo em Linguística Cognitiva (LC). Ou seja, para Gibbs (2009), tal fragilidade se dá porque as pesquisas em LC estariam baseadas em exemplos não autênticos, elaborados pelo próprio linguista; como também em processos de introspecção a partir dos quais não seria plausível acessar processos inconscientes por meio de nossa consciência.

Com efeito, para Gibbs:

[Haveria] diferentes níveis nos quais a 'compreensão linguística' pode ser estudada e explicada, [fazendo com que reconheçamos] que [os] métodos de análise consciente e sistemática de expressões linguísticas não podem fornecer os insights necessários para a produção ou processamento 'automático' da linguagem (2009, p. 202)

Dessa forma, o autor nos propõe vários desafios metodológicos dentre os quais: o de detalhar de maneira mais rigorosa os nossos procedimentos investigativos para que possam ser mais adequados a testes experimentais. Na tentativa de acatar tais ponderações, decidimos constituir corpora com base em exemplos de uso real da expressão convencional cabra em diferentes gêneros textuais bem como formulamos perguntas nos cinco questionários em torno de temas investigados por Gibbs (2009): (i) o exame das imagens mentais dos respondentes a respeito das expressões convencionais; (ii) a avaliação dos julgamentos por parte dos respondentes acerca do significado metafórico da 
expressão convencional cabra em diferentes gêneros textuais.

Finalmente, para o desenho de nosso tipo de pesquisa, levamos, igualmente, em consideração a orientação de Lakoff (1987), qual seja: "uma das coisas mais importantes que a LC [Linguística Cognitiva] tem a oferecer a outras vertentes das Ciências da Cognição é a metodologia de como estudar tanto a linguística como a estrutura conceptual” (p. 379). Nessa perspectiva, desenvolvemos o nosso estudo de forma detalhada com vistas que ele possa ser abordado por outras técnicas. Ou seja, pretendemos, ao adotar um tipo de pesquisa qualiquantitativa, contribuir para as discussões metodológicas no âmbito da LC e por extensão no âmbito das demais Ciências da Cognição. Ora porque avaliamos que o resultado do tratamento quantitativo de boa parte dos dados coletados por meio da aplicação de cinco questionários poderia suscitar questões a serem aprofundadas qualitativamente; Ora porque estimamos que nossa análise qualitativa realizada com base nos dados reunidos pelos nossos corpora poderia despertar problemas a serem investigados quantitativamente.

\section{Referências}

CABOCLO, Manoel. Manoel caboclo. São Paulo: Editora Hedra, 2000.

CASCUDO, Luís Câmara. Coisas que o povo diz. 2. ed.São Paulo: Globo Editora, 2009. 1. ed., 1968.

CASTRO, Nei Leandro de. As pelejas de ojuara:o homem que desafiou o diabo. São Paulo: Editora ARX, 2006.

FELTES, Heloísa Pedroso de Moraes. Semântica cognitiva:ilhas, pontes e teias. Porto Alegre: Edipurcs, 2007.

FERREIRA, Aurélio Buarque de Holanda. Dicionário Aurélio da Língua Portuguesa. 5 ed. Editora Positivo, 2004.

FREYRE, Gilberto.Nordeste. 7. ed. São Paulo: Global Editora, 2004. 1. ed, 1937.

GADELHA, Marcus. Dicionário de cearês. Fortaleza: Multigraf.1999.
GEERAERTS, Dirk. A prática definitória dos dicionários e a concepção semântico-cognitiva de polissemia. In: SIQUEIRA, Maity (Org.). Cadernos de Tradução. Porto Alegre. n 25. p. 55-76, jul-dez. 2009.

GIBBS, Raymond. Porque a linguística cognitiva deveria se preocupar mais com métodos empíricos. In: SIQUEIRA, Maity (Org.). Cadernos de Tradução. Porto Alegre. n. 25, p.193-215, jul-dez. 2009.

GRADY, Joseph.Foundations of meaning: primary metaphors and primary scenes. 1997. PhD Dissertation. Graduate Division, University of California, Berkeley, 1997.

JOHNSON, Mark. Philosophy's debt to metaphor. In: GIBBS,Raymond (Ed.). The Cambridge handbook of metaphor and thought. NewYork: Cambridge University Press, 2008. p. 39-52.

KLEIN, Devorah E.; MURPHY, Gregory L.The representation of polysemous words.Journal of Memory and Language, n. 45, p. 259-282, 2001.

KÖVECSES, Zoltán.Metaphor: a practical introduction. 2. ed. Oxford: Oxford University Press, 2010.

LAKOFF, George. Women, fire and dangerous things: what categories reveal about the mind. University of Chicago Press, 1987.

LAKOFF, George; JOHNSON, Mark.Metáforas da vidacotidiana.São Paulo: EDUC e Mercado das Letras, (1980), 2002.

LAKOFF, George; TURNER, Mark.More than cool reason: a field guide to poetic metaphor. Chicago: Universityof Chicago Press, 1989.

MACEDO, Ana Cristina Pelosi de. Cognição e linguística. In: MACEDO, Ana Cristina Pelosi de; FELTES, Heloísa Pedroso de Moraes; FARIAS, Emília Maria Peixoto (Orgs.). Cognição e linguística: explorando territórios, mapeamentos e percursos. Porto Alegre: Edipucrs, 2008. p. 9-37.

NETO, Lira. Padre cícero: poder, fé e guerra no sertão. São Paulo: Companhia das Letras, 2009.

OLIMPIO, Domingos. Luzia homem. São Paulo: Editora Moderna. 1984.

PONTES, Carlos Gildemar. Super dicionário de cearensês. Fortaleza: Edições Livro Técnico. 2000.

RÊGO, José Lins do. Fogo morto. 21. ed. Rio de Janeiro: Livraria José Olympio Editora, 1982.

$\mathrm{ROSCH}$, Eleanor et al. Basic object in natural categories.CognitivePsychology, n.8. p. 382-439, 1976.

SARAIVA, Andréa. Orélio cearense. Fortaleza: Edições Livro Técnico, 2001. 
SILVA, Augusto Soares da.O mundo dos sentidos em português - polissemia,semântica e cognição. Coimbra: Almedina, 2006.

WITTGENSTEIN, Ludwig. Tratado lógicofilosófico/Investigações filosóficas. Lisboa. Fundação CalousteGulbenkian, 1987.

SUASSUNA, Ariano. Auto da compadecida. 35. ed. Rio de Janeiro: Editora Agir. 2005. 1. ed, 1927. 


\section{ANEXO}

\section{ANEXO A}

\section{Quadro 1 - Questionário Instrumento}

\begin{tabular}{|c|c|}
\hline PERGUNTAS & RESPOSTAS \\
\hline $\begin{array}{l}\text { 1. O que lhe vem à mente quando você } \\
\text { ouve a palavra CABRA? Liste as palavras } \\
\text { que lhe vem à cabeça. }\end{array}$ & $\begin{array}{l}\text { 45\% responderam Animal; } \\
\text { 15,2\% responderam Homem; } \\
\text { 9,1\% responderam Cabra da Peste e } \\
\text { Leite; } 6,1 \% \text { responderam Macho. } \\
\text { 6,1\% não responderam; } \\
3 \% \text { responderam Carneiro } \\
3 \% \text { responderam Ladrão e Zona Rural. }\end{array}$ \\
\hline $\begin{array}{l}\text { 2. Você acredita que o termo CABRA é } \\
\text { usado para designar individuo do sexo } \\
\text { masculino? }\end{array}$ & 93,9\% responderam SIM. \\
\hline $\begin{array}{l}\text { 3. O que é para você verdadeiramente um } \\
\text { cabra? Ordene os termos abaixo numa lista. } \\
\text { (Cabra Macho, Cabra da Peste, Cabra Bom, } \\
\text { Homem, Cabra Raparigueiro, Cabra Véi, } \\
\text { Um sujeito qualquer e Capanga) }\end{array}$ & $\begin{array}{l}\text { 1. } 33,3 \% \text { apontaram Homem } \\
\text { 2. } 36,4 \% \text { apontaram Cabra Macho } \\
\text { 3. } 24,2 \% \text { apontaram Cabra da Peste. } \\
\text { 4. } 27,3 \% \text { apontaram Cabra Bom. } \\
\text { 5. } 18 \% \text { apontaram ou Cabra da Peste, } \\
\text { ou Cabra Bom ou Cabra Raparigueiro. } \\
\text { 6. } 33,3 \% \text { apontaram Cabra vei. } \\
\text { 7. } 33,3 \% \text { apontaram Capanga. } \\
\text { 8. } 33,3 \% \text { apontaramCapanga. }\end{array}$ \\
\hline
\end{tabular}

Fonte: Quadro elaborado pela autora. 


\section{Quadro 2 - Questionário 1}

PERGUNTAS
$\begin{aligned} & \text { 1. Você acredita que o homem e a mulher são animais? } \\ & \text { 2. Se você acredita que tanto o homem quanto a mulher } \\ & \text { são animais, qual seria a diferença entre homem/mulher } \\ & \text { animal e os demais animais? }\end{aligned}$

3. Você acredita que haja diferenças entre o homem brasileiro nordestino e o homem brasileiro no geral? Porquê?

4. Você concorda com a definição segunda a qua CABRA se refere a: Qualquer indivíduo/sujeito de sexo masculino/ Qualquer indivíduo/sujeito de sexo masculino brasileiro/Apenas, algum tipo de indivíduo/sujeito de sexo masculino brasileiro.

5. Você acha que a expressão CABRA DAPESTE e CABRA MACHO se referem a:Qualquer indivíduo/sujeito de sexomasculino/ Qualquer indivíduo/sujeito de sexo masculino brasileiro / Qualquer indivíduo/sujeito de sexo masculino brasileiro e nordestino

6. Você acha que CABRA é usado também para se referir: Qualquer indivíduo de sexo feminino/Qualquer indivíduo de sexo feminino brasileiro/Apenas alguns indivíduos de

sexo feminino brasileiro/Só se refere a individuo do sexo masculino

7. Quando você ouve a expressão CABRA BOM, que tipo de imagem lhe vem à cabeça?
RESPOSTAS

$97 \%$ responderam SIM

22 dos 30 participantes mencionaram a racionalidade como traço distintivo entre o homem e os demais animais.

$70 \%$ responderam SIM

$43 \%$ apontaram qualquer individuo de sexo masculino e $43 \%$ apontaram apenas algum tipo de individuo brasileiro de sexo masculino

$66 \%$ apontaram para qualquer individuo brasileiro nordestino de sexo masculino.

$86,7 \%$ disseram que a expressão só se refere a individuo de sexo masculino.
8. Você concorda com a definição segundo a qual CABRA é um representante da mistura entre mulato e negro?

9. Você concorda com definição segundo a qual CABRA é um jagunço?
10. Você concorda com a definição segundo a qual CABRA é um habitante da zona rural?

11. Você concorda com a definição segundo a qual CABRA é um cangaceiro?

12. Você concorda com a expressão que diz que "Não há doce ruim e CABRA bom"?

13. "Não me mete medo! Vá dizer a este mata-cachorro que eu agüento. Sou homem, cabra. Sou homem!" Ao ler essa passagem do romance FOGO MORTO, de José Lins do Rego, você acha que essa idéia de homem é adequada, é real?

Fonte: Quadro elaborado pela autora.
$73,3 \%$ disseramque NÃO

$60 \%$ disseram NÃO

Todos os participantes evocaram imagem positiva do cabrabom.Grande parte mencionou qualidade de caráter e habilidoso.

$86,7 \%$ disseramque NÃO

73,3\% disseram NÃO

$76,7 \%$ disseram NÃO

$56,7 \%$ disseram SIM 


\section{Quadro 3 - Questionário 2}

PERGUNTAS
1. Vocêgosta de animais?
2. Vocêcriaalgum animal?
3. Você tem ou já teve algum contato direto com Cabra?

4. Quando você pensa em Cabra o que Ihe vem à mente?

5. Você associa Cabra a alguma simbologia?

6. Qual seria para você uma característica marcante de Cabra?

\section{RESPOSTAS}

$86,7 \%$ responderam SIM

$53,3 \%$ responderam SIM

$70 \%$ responderam SIM

10 dos 30 participantes apontaram para a imagem de animal (como, da própria cabra, do bode, de um animal com chifres, briguento ou de algo correlato como o berro e o leite. Há menção à zona rural como, fazenda, duas menções; sertão e interior, uma menção respectivamente; bem como a imagem de homem (machista, cabra da peste, cabra macho).

$56,7 \%$ responderam SIM

A característica marcante da cabra foi o berro, com sete menções. As demais características citadas foram chifres e resistência, com três menções, respectivamente; cheiro, com duas menções; valentia, temperamento forte, teimosia, persistência em resistir, leite, chifradas, e curiosamente safadeza, com uma menção respectivamente.

$63,3 \%$ responderam NÃO

7. Você conhece alguma historia interessante com Cabra?

8. Você acha que Cabra estaria mais associada a alguma região do Brasil?

$86,7 \%$ responderam SIM e 73,3\% apontaram o Nordeste como região

$50 \%$ responderam SIM

9. Você vê alguma função especifica de Cabra para o contexto sociocultural em que vive?

10. Você acha que Cabra tem algum atributo que o relacione com a idéia de companheirismo?

11. Você acha que Cabra tem algum atributo que o relacione com a idéia de violência?

$50 \%$ responderam NÃO

12. Você acha que Cabra tem algum atributo que o relacione com a idéia de valentia?

$66,7 \%$ responderam SIM

13. Você acha que Cabra tem algum atributo que o relacione com a ideia de virilidade?

14. Você acha que Cabra representa melhor o gênero masculino ou feminino?

15. Você gosta do cheiro de cabra?

16. O que você acha da aparência de Cabra? Você a acha um belo animal?

Fonte: Quadro elaborado pela autora.
$50 \%$ responderam NÃO

$70 \%$ responderam NÃO

$50 \%$ responderam NÃO

$46 \%$ apontaram o sexomasculino

$60 \%$ responderam SIM 


\section{Quadro 4 - Questionário 3}

\begin{tabular}{|c|c|}
\hline PERGUNTAS & RESPOSTAS \\
\hline 1. Você acredita que o homem é umanimal? Porquê? & $86,67 \%$ responderam SIM \\
\hline $\begin{array}{l}\text { 2. Você acredita que o homem possa ser representado } \\
\text { por um animal? Qualseria e } \\
\text { Porquerazão? }\end{array}$ & $\begin{array}{l}53,3 \% \text { responderam NÃO e } 60 \% \text { não indicou nenhum } \\
\text { animal }\end{array}$ \\
\hline $\begin{array}{l}\text { 3. Você concorda com que a imagem do homem } \\
\text { nordestino seja representada por } \\
\text { Cabra? }\end{array}$ & $50 \%$ responderam NÃO \\
\hline $\begin{array}{l}\text { 5. Em sua opinião, qual seria o aspecto físico relativo } \\
\text { aCabra que você acredita que, em alguma medida, se } \\
\text { assemelharia a de um homem? }\end{array}$ & $\begin{array}{l}16 \text { dos } 30 \text { participantes declararam não haver nenhum } \\
\text { aspecto ou se abstiveram. Quando o fizeram apontaram } \\
\text { olhos, com três menções e barbicha, com duas menções. }\end{array}$ \\
\hline $\begin{array}{l}\text { 6. Em sua opinião, qual seria o aspecto moral ou } \\
\text { comportamental relativo à Cabra que, em alguma medida, } \\
\text { se assemelharia a de um homem? }\end{array}$ & $\begin{array}{l}9 \text { dos } 30 \text { participantes declararam não haver nenhum } \\
\text { aspecto ou se abstiveram.Quando o fizeram, apontaram } \\
\text { para temperamento forte,com quatro menções; teimosia, } \\
\text { com três menções; e brutalidade, com duas menções. }\end{array}$ \\
\hline $\begin{array}{l}\text { 9. Você acha que o Cabra tem nacionalidade ou } \\
\text { naturalidade específica? }\end{array}$ & $\begin{array}{l}53,3 \text { \% responderam SIM e } 46,7 \% \text { não mencionaram a } \\
\text { região contra } 40 \% \text { que apontaram a região Nordeste. }\end{array}$ \\
\hline
\end{tabular}

Fonte: Quadro elaborado pela autora. 


\section{Quadro 5:Questionário 4}

\begin{tabular}{l|l}
\hline PERGUNTAS & RESPOSTAS \\
\hline $\begin{array}{l}\text { 1. Você acredita que o homem é um animal? Porquê? } \\
\text { 2. Você acredita que o homem possa ser representado } \\
\text { por um animal? Qualseria e Porquerazão? }\end{array}$ & $60 \%$ responderam SIM. \\
\hline $\begin{array}{l}\text { 3. Você concorda com que a imagem do homem } \\
\text { nordestino seja representada por Cabra? }\end{array}$ & $50 \%$ responderam NÃO. \\
\hline $\begin{array}{l}\text { 4. Você vê alguma diferença quando um homem } \\
\text { (nordestino?) é chamado de Cabra ao invés de somente } \\
\text { "Homem", "Cara", "Rapaz"? Qualseriaessadiferença? }\end{array}$ & $73,3 \%$ responderam SIM. \\
\hline $\begin{array}{l}\text { 5. Em sua opinião, qual seria o aspecto físico relativo } \\
\text { aCabra que você acredita que, em alguma medida, se } \\
\text { assemelharia a de um homem? }\end{array}$ & $\begin{array}{l}17 \text { dos } 30 \text { participantes, ao serem declararam "não haver } \\
\text { apontaram para baixa estatura, em quatro menções; } \\
\text { resistência, em duas menções. }\end{array}$ \\
\hline
\end{tabular}

6. Em sua opinião, qual seria o aspecto moral ou comportamental relativo à Cabra que, em alguma medida, se assemelharia a de um homem?
12 entre os 30 participantes não mencionaram nenhum aspecto ou disseram não saber. Os demais participantes mencionaram resistência, três vezes; teimosia, três vezes; e força, duas vezes.

7. Você acredita que seus pares (Avô, Pai, Marido, Companheiro, Amigos íntimos e em geral) possam ser chamados por você de Cabra? Porquê?

8. Você acredita que homens com os quais você não tem intimidade (Chefe, colegas de trabalho, anônimos na rua e no comércio e prestadores de serviços e autoridades de um modo geral) possam ser chamados por você de Cabra? Porquê?

9. Você acha que o Cabra tem nacionalidade ou naturalidade específica?

$60 \%$ responderam SIM.

76,7\% responderam NÃO.

10. Você se vê representado por algum animal? Qualseria? Porquê?

43,3\% responderam SIM e 43,3\% responderam NÃO.

Fonte: Quadro elaborado pela autora. 